\section{Meeting the National Needs for Minority Scholars and Scholarship: What Professional Associations Might Do}

\author{
John A. Garcia, University of Arizona \\ Robert C. Smith, San Francisco State University
}

For a period of several years, a group of scholars has examined the status of minority scholars and scholarship in the United States. In 1987 , an invitational conference on the status of minority faculty was sponsored by the Graduate School of the State University of New York at Stunybrook. Held at the Harrison Conference Center on Long Island, the participants included more than one hundred minority and nonminority faculty, administrators, and graduate students. For three days, the group discussed the causes, consequences, and remedies to the problem of declining minority participation in the scholarly enterprise. At the end of the conference, a small planning task force (which has met several times since the invitational conference) was established under the leadership of Dr. Myrna Adams, Associate Dean at the Stonybrook Graduate School, to develop policies and recommendations based on the conference findings. In addition, the task force developed strategies for the implementation of the recommendations. The purpose of this essay is to discuss the findings and recommendations of the task force. It focuses on the role of professional associations in the production of minority scholars and scholarship and support of the participation of minority scholars in academia, as well as on the shrinking pool of minorities in graduate programs.

\section{The Objectives}

The minority group members which are the focus of our concern are African Americans, Native Americans, and Latinos. Data from the HEGIS files (Higher Education Graduate Information Survey) and a variety of other sources indicate that the number of African Americans in graduate schools has declined; while the number of Native Americans and Latinos has remained relatively stable. The distribution of minorities in the academy (both faculty and graduate students) is skewed toward education and the social sciences; but even in these disciplines, the number of Ph.D.'s produced annually is usually less than fifty. In Political Science, the proportion of minority Ph.D.'s is still less than five percent of the profession; and unless concerted action is taken, this situation is not likely to change. (For data and analysis on African Americans in the discipline see Woodard and Preston, 1984, 1985.)

The objectives of the Task Force are to promote the goals to enhance the production of minority scholars and scholarship by appealing on the basis of a national need to federal and state governments, umbrella academic organizations, university administration and individual faculty members and disciplined-based professional associations. The contents of the Task Force agenda are diverse, including: (1) increasing the production of minority scholars through graduate training; (2) the promotion of minority scholarship through the encouragement of diverse research agendas and methodologies; (3) the development of a minority talent pool; (4) the expansion of targeted financial support for minority graduate study; (5) redefining and reshaping research policies and practices; (6) strengthening the placement activities and employment of minority scholars; (7) the encouragement of self-conscious mentoring process in graduate education; (8) a self-conscious awareness of hiring, promotion and tenure policies and practices that may constitute barriers to the effective utilization of minority scholars and scholarship; and (9) develop and maintain an accurate data base on minority student progress and completion of graduate education.

\section{The Role of \\ Professional Associations}

Professional associations play a key role in the formation and promulgation of acceptable standards, the dissemination of information and knowledge, and defining criteria of excellence. The goals and values of Political Science or Physics or any other discipline are influenced by the activities, and leadership cues of its associations. Thus the Task Force report proposes a number of recommendations that professional associations can adopt to achieve the goals of expanded utilization of minority scholars and scholarship. Some of these recommendations include: (1) insure significant minority representation among referees for articles, on review boards and editorial boards; (2) set quantifiable goals for minority participation in all aspects of the discipline; (3) encourage new ways of thinking and new theoretical perspectives that may emerge from minority scholarship; (4) provide mechanisms and forums for the critical analysis of the discipline's objectives in the light of the problems and concerns of minority peoples; (5) develop channels for potential minority leadership through mentoring, internships, fellowships, committee appointments, etc.; (6) insure that the agenda of professional meetings reflects an effort to integrate, not isolate, topics, approaches and research priorities of concern to minorities; and (7) develop and maintain contact with minority discipline oriented organizations (i.e., National Association of Black Political Scientists, National Association of Chicano Studies, for examples) and seek development with these associations of joint projects and publications.

The underlying premise in all of these recommendations is that an active role of the association leadership is necessary in order for the goals of expanding the number and participation of minority scholars in the academy are to be met. Such efforts by the leaders of national and regional associations could help to activate individual departments and to adopt practices to achieve such goals. The role of faculty might 
include enhanced outreach and recruitment efforts in minority communities and a constant monitoring of the admissions process to assure sensitivity, fairness and equity. In this latter area, such activities might include a regular review criteria and procedures for admission in order to assure their predictive validity for minority applicants. On the issue of outreach and recruitment, departments and faculty might seek the early identification of talented minority undergraduates or even promising students in local high schools, and provide support so that they might consider academic careers. Finally, more attention might be paid, selfconsciously, to promote effective mentoring of minority students, especially by senior faculty, from initial recruitment, study, graduation, first appointment, and subsequent career development and advancement. For example, a significant percentage of minority graduate students are found in terminal Master's programs. These programs may serve as talent pools from which to recruit prospective Ph.D. students.

While mentoring is recognized as a critical element in successful development of academicians, most faculty do not have the knowledge and training to be effective mentors. There is a need for the development of mentoring workshops and understanding the particular needs and perspectives of minority students. The Association and departments should encourage all faculty to serve as mentors, as well as hold individuals accountable for the quality of a student's training and growth.

Faculty should be encouraged by Association leadership to carefully and consistently evaluate criteria for appointments, promotion and tenure to be certain that they do not unfairly disadvantage minorities and minority scholarship. While objectivity is a major factor in the areas of research productivity, teaching, and university and community service, these decisions may also include dimensions of subjectivity and bias that work to the disadvantage of minority group faculty members. For example, minority scholars in the social sciences may work on unconventional or non-traditional topics or publish in non-discipline based journals (i.e., Phylon, Review of Black Political Economy, Hispanic Journal of Behavioral Sciences, etc.). This may lead more traditional faculty to discount the contributions of these works. The key is the ability of faculty to evaluate research on the basis of its theoretical, methodological, and substantive merit rather than on the basis of the discipline's traditional outlets.

Finally, in the area of scholarship, the sense of openness by scholars, the journals, and the association to minority research issues and perspectives is essential to overcoming barriers, real and perceived, and to the development of minority scholars and scholarship.

\section{Summary}

In a very brief amount of space, this paper has laid out some central issues raised by an active core of scholars. The next generation of scholars and teachers is soon upon us. At the same time, the presence and impact of minority scholars is very limited. In the expansion of the academy, concerted and cooperative efforts to respond to the national need for minority scholars and scholarship requires immediate attention. Several educational organizations and associations have established efforts in these areas with tentative results. The purpose of this Task Force and other individuals sharing these concerns and goals is to place on the educational establishment's agenda the need to direct attention and action in this area. Through coopera- tive efforts, there is a greater possibility that concrete results and goals can be achieved. More dialogues with associations and its membership is an important first step.

\section{Note}

It should be clear that our principal concern is to increase the representation of minority scholars in the academy. We believe that by doing so the dominant research agendas of the disciplines will be broadened and enriched as these scholars bring to their works the pluralist perspectives derived from their unique backgrounds and experiences. Yet, our concern is not just more minority scholars, but the inclusion in the disciplines of theoretical and minority group experiences. Such inquiries are frequently conducted by minority scholars, but also by EuroAmericans. We encourage the inclusion of such new perspectives from all parts of the academy. In addition, we do not expect, nor do we wish minority scholars to work exclusively on minority problems in their fields. On the contrary, when minorities are included equitably on university faculties, we would expect them to work on the range of problems of their disciplines, bringing their background and experiences to the tasks. In sum, the objective is a multi-ethnic faculty that reflects in its research and teaching the diversity of the group histories and experiences that constitute the United States.

\section{References}

Woodard, M. and M. Preston. 1984. "The Rise and Decline of Black Political Scientists in the Profession," PS 17: 787-92. 1985. "Black Political Scientists: Where Are the New Ph.D.?" PS 18: 80-88.

\section{About the Authors \\ John A. Garcia is Associate Professor and Department Head of Political Science at the University of Arizona. Robert C. Smith is Professor of Political Science at San Fran- cisco State University. They are both mem- bers of the policy planning task force on Meeting the National Need for Minority Scholars.}

